\title{
Inhibitory effects of Lactobacillus casei Shirota against both Candida auris and Candida spp. isolates that cause vulvovaginal candidiasis and are resistant to antifungals
}

Aline Lorenzoni Paniágua', Amabel Fernandes Correia², Lívia Custódio Pereira³, Bruna Maciel de Alencar', Fabiana Brandão Alves Silva', Rosane Mansan Almeida ${ }^{1 *}$ (D) and Yanna Karla de Medeiros Nóbrega ${ }^{1}$

\begin{abstract}
Background: Vulvovaginal candidiasis (WC), the second leading cause of genital infection in women of reproductive age, is caused by yeasts of the genus Candida. Treatment is usually empirical and performed with azoles, which have shown increasing ineffectiveness due to resistance from these species. This therapeutic challenge has led to the search for new treatment strategies. Lactobacillus spp. produce several components with microbicidal effects, such as lactic acid. These species are the main components of a healthy vaginal microbiota and have been used as probiotics. The aim of this work was to investigate the in vitro inhibitory effects of Lactobacillus casei Shirota on both the Candida spp. that cause WC and on C. auris.

Methods: The microbicidal effects of $L$. casei Shirota on the main WC-causing species, C. albicans, C. tropicalis, C. norvegensis and C. parapsilosis, in addition to C. auris were investigated by counting the Colony-forming Units (CFUs) after cocultivation. The antifungal activity of lactic acid against these Candida strains was assessed using the microtiter broth dilution method to determine the minimum inhibitory concentrations (MICS). The effects of $L$. casei Shirota on hyphal and early biofilm formation was measured by optical microscopy.

Results: L. casei Shirota showed inhibitory action against all tested Candida spp., ranging from 66.9 to $95.6 \%$ inhibition depending on the species. This inhibition is possibly related to the production of lactic acid, since lactic acid has shown microbicidal action against these same Candida spp. at a concentration of $5 \mathrm{mg} / \mathrm{mL}$, which corresponds to half of the normal physiological concentration. In addition, L. casei Shirota was able to reduce the formation of $C$. albicans hyphae and early biofilms, showing strong anti-Candida effects.
\end{abstract}

Conclusions: These results suggest that $L$. casei Shirota has antifungal activity against the Candida species that cause WC. L. casei also has microbicidal action against C. auris.

Keywords: Candidiasis, Candida spp., Lactobacillus casei Shiota, Microbicidal effect, Biofilm, C. auris

\footnotetext{
*Correspondence: rmansan@gmail.com

${ }^{1}$ Clinical Microbiology and Immunology Laboratory, Department of

Pharmacy, University of Brasilia, Campus Darcy Ribeiro, Brasilia, DF 70910-900,

Brazil

Full list of author information is available at the end of the article
}

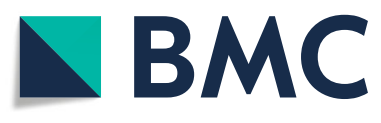

(c) The Author(s). 2021 Open Access This article is licensed under a Creative Commons Attribution 4.0 International License, which permits use, sharing, adaptation, distribution and reproduction in any medium or format, as long as you give appropriate credit to the original author(s) and the source, provide a link to the Creative Commons licence, and indicate if changes were made. The images or other third party material in this article are included in the article's Creative Commons licence, unless indicated otherwise in a credit line to the material. If material is not included in the article's Creative Commons licence and your intended use is not permitted by statutory regulation or exceeds the permitted use, you will need to obtain permission directly from the copyright holder. To view a copy of this licence, visit http://creativecommons.org/licenses/by/4.0/ The Creative Commons Public Domain Dedication waiver (http://creativecommons.org/publicdomain/zero/1.0/) applies to the data made available in this article, unless otherwise stated in a credit line to the data. 


\section{Background}

Vulvovaginal candidiasis (VVC) is the second leading cause of genital infection in women after only bacterial vaginosis [1]. VVC affects up to $78 \%$ of women of reproductive age [2], impairing their quality of life [3]. The main causative agent is Candida albicans, although there has been a recent increase in the incidence of VVC cases caused by other species, such as Candida glabrata, Candida tropicalis, Candida krusei, Candida parapsilosis and Candida guilliermondii [4, 5].

In clinical practice, treatment is usually empirical, and fluconazole is the drug of choice [6]. However, an increasing proportion of Candida strains are resistant to this treatment [7]. This resistance, in addition to the toxicity of some azoles $[8,9]$, has led to the search for alternative therapies to treat VVC.

Anti-Candida properties, such as the suppression of inflammatory genes [10] and the reduction in adherence and biofilm formation [11, 12], have been attributed to Lactobacillus strains. The production of several substances with microbicidal action - such as acetic acid, bacteriocins, biosurfactants, hydrocarbons, hydrogen peroxide, coaggregation molecules [13] and lactic acid have also been reported. Among them, lactic acid is considered the most important postbiotic substance [14].

The vaginal microbiota plays an important role in preventing infections. Lactobacillus spp. are predominant in approximately $70 \%$ of healthy women [15], but some species may not play a protective role [16]. The intestine is a reservoir for microorganisms that access the lower genital tract through the perianal region [17]. Thus, oral administration of Lactobacillus probiotics alters the intestinal microbiota of the rectum and consequently may alter the vaginal microbiota. This strategy can be a useful measure to treat VVC. Although L. casei Shirota is one of the most commonly consumed probiotic strains worldwide, to the best of our knowledge, there have been no studies regarding its action against Candida strains involved in VVC. The aim of this work was to investigate the inhibitory effects of $L$. casei Shirota against strains of Candida spp. isolated from VVC cases and also the effects of $L$. casei Shirota against $C$. auris.

C. auris is an emerging multiresistant pathogen that causes severe infections for which treatment resources are scarce [18]. An L. paracasei strain was recently shown to have both probiotic and postbiotic action against $C$. auris in an in vivo model [19]. Moreover, depending on the method employed, $C$. auris can be misidentified as $C$. parapsilosis or $C$. guilliermondii, two VVC-causing species [18].

\section{Methods}

\section{Origin, isolation and maintenance of the strains}

Candida spp. isolates were obtained from patients examined at the Gynecology Outpatient Service of the
University of Brasilia Hospital (HUB) and identified at the Central Public Health Laboratory of the Federal District (LACEN-DF). We sought and obtained individual written informed consent from all subjects. For this study, clinical isolates of C. albicans, C. glabrata, C. tropicalis, C. krusei, C. parapsilosis and C. norvegensis that showed resistance to one or more antifungals were selected. The multiresistant strain of $C$. auris used in this study was kindly provided by LACEN-DF. Candida cells were routinely maintained on Sabouraud dextrose agar (1\% peptone, $4 \%$ dextrose and $1.5 \%$ agar) or YM broth (1\% glucose, $0.3 \%$ malt extract, $0.5 \%$ peptone and $0.3 \%$ yeast extract) [20]. The Lactobacillus casei Shirota strain was isolated from fermented milk (L. casei Shirota, Yakult $^{\oplus}$, lot number $\left.\mathrm{H} 1336\right)$ and maintained in MRS medium (1\% peptone, $1 \%$ meat extract, $0.5 \%$ yeast extract, $2 \%$ dextrose, $0.5 \%$ sodium acetate, $0.1 \%$ polysorbate $80,0.2 \%$ potassium phosphate, $0.2 \%$ ammonium citrate, $0.01 \%$ magnesium sulfate and $0.005 \%$ manganese sulfate) [21].

The isolates were identified by matrix-assisted laser desorption ionization time-of-flight (MALDI-TOF) mass spectrometry. Briefly, a few colonies were applied to the target slide (Biomérieux, Marcy l'Etoile, France) with $0.5 \mu \mathrm{L}$ of $25 \%$ formic acid and $1 \mu \mathrm{L}$ of $3.1 \%$ matrix solution (alpha-cyano-4-hydroxycinnamic acid) (both from Biomérieux, MarcyI'Etoile, France). After drying, the slides were transferred to a Vitek $\mathrm{MS}^{\diamond}$ System reading station (Biomérieux, Marcy l'Etoile, France), and the obtained spectra were analyzed using the Vitek MS Version 3.0 database. The results were considered valid when the percent probability of identification values were greater than or equal to $99.9 \%$ [22].

\section{Fungicidal activity in coculture}

L. casei Shirota/Candida spp. cocultures were generated according to Kang et al. [21] with modifications. First, $L$. casei Shirota and Candida spp. strains were grown separately in MRS broth at $37^{\circ} \mathrm{C}$ for $24 \mathrm{~h}$ and in YM broth at $37^{\circ} \mathrm{C}$ for $18-24 \mathrm{~h}$, respectively. For cocultures, both $L$. casei Shirota and Candida strains were equally (1:1) inoculated in tubes containing $5 \mathrm{~mL}$ of mixed YM/MRS broth $(\mathrm{v} / \mathrm{v})$ and incubated at $37^{\circ} \mathrm{C}$ for $24 \mathrm{~h}$. The starting inocula - $1 \times 10^{8}$ cells each - were adjusted to an OD600 (optical density at $600 \mathrm{~nm}$ ) in a volume of 5 to $20 \mu \mathrm{L}$. The $\mathrm{pH}$ was measured prior to and after incubation of the cocultures. Candida spp. strains $\left(1 \times 10^{8}\right.$ cells) were incubated by themselves (monocultures) for use as positive controls. Non-inoculated medium was used as a negative control. After growth, $10 \mu \mathrm{L}$ of the cocultures were diluted 1:20, seeded in Petri plates containing YM and MRS media and incubated at $37^{\circ} \mathrm{C}$ for $24 \mathrm{~h}$. Determination of the microbicidal activity of $L$. case $i$ against Candida species was assessed by counting the number 
of colony-forming units per milliliter (CFUs/mL). All samples were tested in technical and biological triplicates (independent experiments).

To evaluate the fungicidal activity of $L$. casei Shirota, the number of CFUs observed in the Candida spp. monocultures (control) were compared to those in the cocultures. Statistical significance of the difference in CFUs between the cocultures and controls was analyzed using Student's t-test. The percentage of microbicidal activity (\%) was calculated employing the following formula:

$\%$ microbicidal activity $=($ CFU cocultivation $\times 100 /$ CFU positive control $)-100$

\section{Dosage of lactic acid}

The lactic acid measurement was performed in the cocultivation broths prior to and after $24 \mathrm{~h}$ of incubation. A filtration step was performed using a $0.2 \mu \mathrm{m}$ filter before the measurements, and the dosage was determined by colorimetry with Cobas 6000 equipment (Roche Diagnostics).

\section{Minimal inhibitory concentration (MIC) of lactic acid by microdilution}

A microdilution assay was performed in 96 -well plates with a volume of $200 \mu \mathrm{L} /$ well and $1 \times 10^{6}$ fungal cells [20]. Serial dilutions of a $2 \%$ DL-lactic acid (Sigma-Aldrich, 69,785) solution were performed to obtain working solutions of 10,5 and $2.5 \mathrm{mg} / \mathrm{mL}$. The microplate was incubated at $35^{\circ} \mathrm{C}$ for $24 \mathrm{~h}$, and $10 \mu \mathrm{L}$ of the content of each well was seeded in YM plates and incubated at $37^{\circ} \mathrm{C}$ for $24 \mathrm{~h}$. All samples and controls were tested in technical triplicates and biological duplicates (independent experiments).

\section{Effects of $L$. casei Shirota on the yeast-to-hyphae transition and early biofilm formation}

To evaluate the effects of $L$. casei Shirota on the yeastto-hyphae transition and initial biofilm formation of Candida spp., cocultures of L. casei/Candida were grown in 96-well flat-bottom polystyrene plates. The experiment was carried out using clinical isolates and the reference C. albicans strains ATCC 90028 and SC5314. In brief, $100 \mu \mathrm{L} /$ well RPMI 1640 medium was supplied with serum $10 \%(\mathrm{v} / \mathrm{v})$ and inoculated with a cell suspension of $1 \times 10^{6}$ yeast and $1 \times 10^{8}$ bacteria per milliliter. The plates were incubated at $37^{\circ} \mathrm{C}$ for $24 \mathrm{~h}$ to obtain early biofilms. Images were captured with either a Nikon Eclipse E200 or an Mrm CCD camera (Carl Zeiss $\mathrm{GmbH}$ ), and the microscope and camera were jointly operated for image capture by Zen 2012 software with $10 \times$ and $40 \times$ objectives.

\section{Statistical analysis}

Statistical analysis was performed by Student's t-test, considering values of $\leq 0.05$ as statistically significant after comparing the tested samples and controls.

\section{Results \\ Anti-Candida activity of $L$. casei Shirota}

The L. casei Shirota strain showed high microbicidal activity against all tested fungal species, inhibiting their growth after $24 \mathrm{~h}$ of coculture. Figure 1 shows the CFU/ $\mathrm{mL}$ counts in YM medium before (monoculture) and after coculture. We obtained the following reduced CFU counts: C. albicans, from 249.6 to $27.6 \mathrm{CFU} / \mathrm{mL}(9 \times)$; C. glabrata, from 447.3 to $149.3 \mathrm{CFU} / \mathrm{mL}(3 \times)$, C. tropicalis, from 99.3 to $4.0 \mathrm{CFU} / \mathrm{mL}(24 \times)$, C. norvegensis, from 138.6 to $38,6 \mathrm{CFU} / \mathrm{mL}(3.5 \times)$, C. krusei, from 126.6 to $20.6 \mathrm{CFU} / \mathrm{mL}(6 \times)$, C. parapsilosis, from 23.6 to 1.3 $\mathrm{CFU} / \mathrm{mL}(18 \times)$ and C. auris, from 23.6 to $4.6 \mathrm{CFU} / \mathrm{mL}$ (5x). Thus, inhibition by $L$. casei Shirota was most effective against $C$. tropicalis and least effective against $C$. auris after analysis in YM medium.

To verify the influence of the medium on the growth inhibition of Candida spp., CFU counts were also performed using MRS medium, which favors the exuberant growth of Lactobacillus spp. while also allowing the growth of yeasts. We obtained the following reduced CFU counts: C. albicans was reduced from 249.6 to 24.3 CFU/mL (10x); C. glabrata, from 447.3 to $187.3 \mathrm{CFU} /$ $\mathrm{mL}(2.4 \times)$; C. tropicalis, from 99.3 to $4.3 \mathrm{CFU} / \mathrm{mL}(23 \times)$; C. norvegensis, from 138.6 to $52.6 \mathrm{CFU} / \mathrm{mL}(2.6 \times) ; C$. krusei, from 126.6 to $20 \mathrm{CFU} / \mathrm{mL}$ (6.3×); C. parapsilosis, from 23.6 to $1.3 \mathrm{CFU} / \mathrm{mL}(18 \times)$; and $C$. auris, from 23.6 to $8.0 \mathrm{CFU} / \mathrm{mL}(3 \times)$. Once again, growth inhibition was most effective against $C$. tropicalis and least effective against $C$. auris. There was no significant difference in the antifungal activity of $L$. case $i$ in the two types of culture media used (Fig. 1). These data confirm the reduction in CFUs/mL of all tested Candida species after coculture with L. casei Shirota (Fig. 1).

The percent microbicidal activity of $L$. casei Shirota against Candida spp. strains (\%) was calculated by setting the positive control as 100\% growth. The microbicidal activities verified in YM medium as percentages were C. albicans $89.2 \%$, C. glabrata $66.9 \%$, C. tropicalis 95.6\%, C. norvegensis 62.7\%, C. krusei $87.0 \%$, C. parapsilosis $90.1 \%$ and C. auris $86.6 \%$ (Table 1). The results obtained in MRS medium were as follows: C. albicans $93.8 \%$, C. glabrata $69.1 \%$, C. tropicalis $95.2 \%$, C. norvegensis $67.3 \%$, C. krusei $85.0 \%$, C. parapsilosis $94.8 \%$ and C. auris $93.9 \%$ (Table 1).

Although the inhibition spectra varied depending on the culture medium and the species involved, in all cocultures, the activity was greater than $60 \%$ and reached 


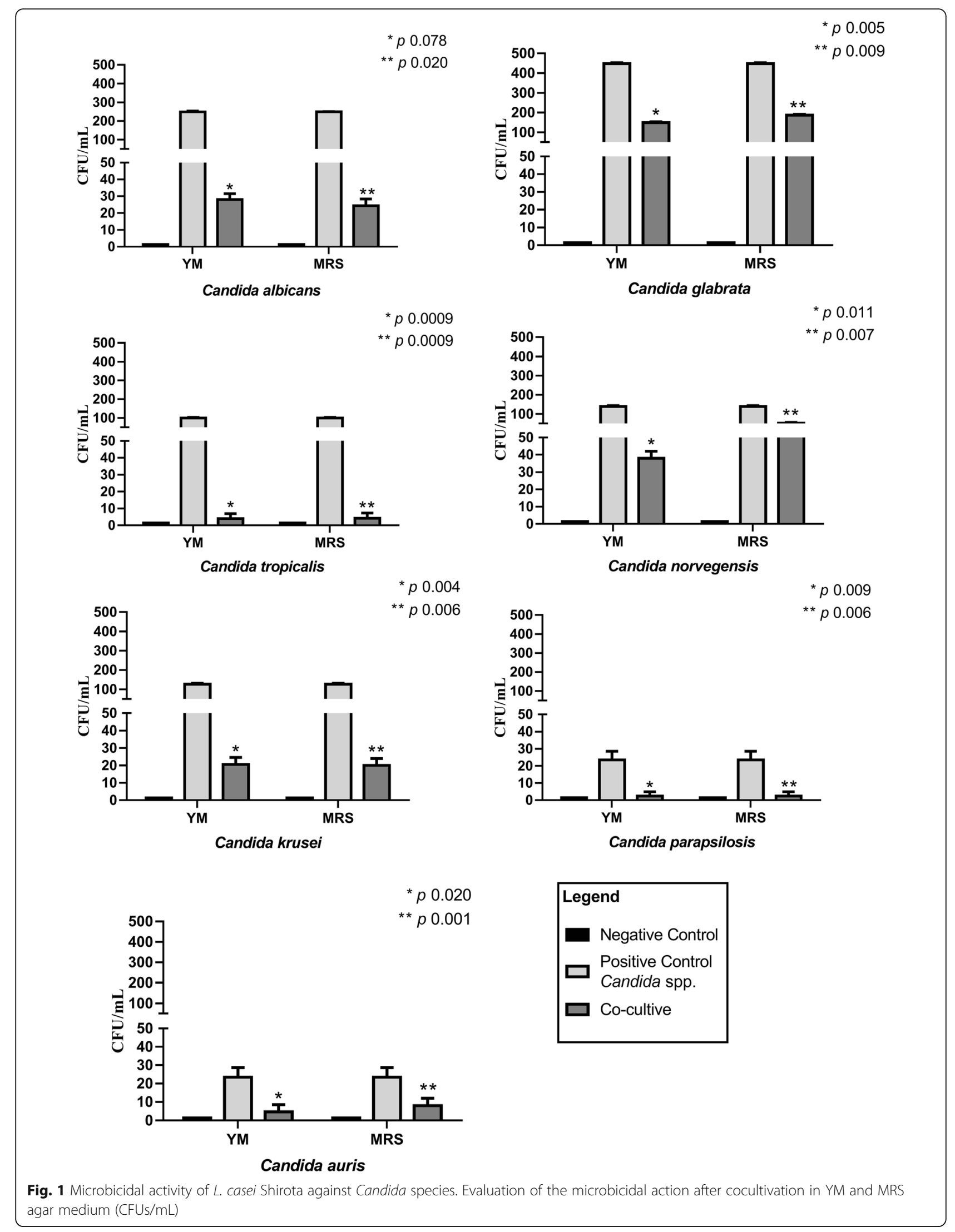


Table 1 Percent inhibition of Candida growth after cocultivation with L. casei Shirota

\begin{tabular}{|c|c|c|c|c|c|}
\hline & \multirow{2}{*}{$\begin{array}{l}\text { PC } \\
\text { Candida } \\
\text { spp. (N) }\end{array}$} & \multicolumn{2}{|l|}{ YM } & \multicolumn{2}{|l|}{ MRS } \\
\hline & & $\begin{array}{l}\text { Cocultivation } \\
\text { Candida spp. }+ \text { L. casei }(\mathrm{N})\end{array}$ & Microbicidal activity (\%) & $\begin{array}{l}\text { Cocultivation } \\
\text { Candida spp. }+ \text { L. casei }(\mathrm{N})\end{array}$ & Microbicidal activity (\%) \\
\hline Candida albicans & 249.6 & 27.6 & 89.2 & 24.3 & 90.8 \\
\hline Candida glabrata & 447.3 & 149.3 & 66.9 & 187.3 & 69.1 \\
\hline Candida tropicalis & 99.3 & 4.0 & 95.6 & 4.3 & 95.2 \\
\hline Candida norvegensis & 138.6 & 38.0 & 62.7 & 52.6 & 67.3 \\
\hline Candida krusei & 126.6 & 20.6 & 87.0 & 20.0 & 85.0 \\
\hline Candida parapsilosis & 23.6 & 1.3 & 90.1 & 1.3 & 94.8 \\
\hline Candida auris & 23.6 & 4.6 & 86.6 & 8.0 & 93.9 \\
\hline
\end{tabular}

PC (Positive control) : Candida spp. monocultures corresponding to $100 \%$ growth

as high as $95.6 \%$. For $C$. auris, the microbicidal activity reached $93.9 \%$.

\section{Production of lactic acid in the cocultures}

The $\mathrm{pH}$ values in the culture medium were evaluated prior to and after the $24 \mathrm{~h}$ incubation period. In all cocultures, the $\mathrm{pH}$ measured ranged from 6.0 to 5.0 after $24 \mathrm{~h}$, while no change in $\mathrm{pH}$ was observed for cultures of Candida isolated in YM medium.

The lactic acid production of the cocultures was then measured. The values obtained for cocultivation were subtracted from the baseline values obtained for Candida strains. Noninoculated YM and MRS media were used as negative controls. Lactic acid production was observed in all evaluated cocultures. The production ranged from 6.51 to $8.24 \mathrm{mg} / \mathrm{mL}$, which is slightly lower than the $10.34 \mathrm{mg} / \mathrm{mL}$ obtained for $L$. casei grown by itself (Table 2).
Minimal inhibitory concentration (MIC) of lactic acid

To confirm the action of lactic acid on the inhibition of Candida growth, three different concentrations (10, 5 and $2.5 \mathrm{mg} / \mathrm{mL}$ ) of lactic acid were evaluated. These concentrations were chosen based on the biological production of Lactobacillus present in the normal healthy microbiota, where the concentration is approximately $10 \mathrm{mg} / \mathrm{mL}$ (1\%) [23].

Table 2 shows the minimal inhibitory concentrations (MICs) of lactic acid against the Candida spp. The lowest tested concentration, $2.5 \mathrm{mg} / \mathrm{mL}$, had an antimicrobial effect against most Candida species, except for $C$. parapsilosis, whose inhibitory concentration was found to be $5 \mathrm{mg} / \mathrm{mL}$. Considering an MIC of $5 \mathrm{mg} / \mathrm{mL}$ ( $50 \%$ of the physiological concentration), lactic acid showed antimicrobial activity against all tested Candida strains. Note that all of the Candida strains in this experiment had previously shown fluconazole resistance.

Table 2 Lactic acid production by L. casei Shirota and minimum inhibitory concentrations of lactic acid

\begin{tabular}{llll}
\hline & Lactic acid production $\mathbf{m g} / \mathbf{m L})$ & MIC \\
\cline { 2 - 4 } & Monocultures (Candida spp.) & Cocultures (+ L. casei) & Lactic acid (mg/mL) \\
\hline YM (NC) & 0 & 0 & NA \\
MRS (NC) & 0 & 0 & NA \\
YM + MRS (NC) & 0 & 0 & NA \\
Lactobacillus casei (PC) & 10.34 & $\mathrm{NA}$ & 2.5 \\
Candida albicans & 0.020 & 7.07 & 2.5 \\
Candida glabrata & 0.019 & 6.51 & 2.5 \\
Candida tropicalis & 0.021 & 7.58 & 2.5 \\
Candida norvegensis & 0.025 & 8.22 & 2.5 \\
Candida krusei & 0.019 & 7.80 & 5.0 \\
Candida parapsilosis & 0.023 & 8.14 & 2.5 \\
Candida auris & 0.021 & 8.24 & \\
\hline
\end{tabular}

YM (NC): YM medium uncultivated/negative control, MRS (NC): MRS medium uncultivated/negative control, YM + MRS (NC): Mixed YM and MRS media uncultivated/negative control, PC: Positive control, NA: Not applicable 


\section{L. casei Shirota impairs the yeast-to-hyphae transition in C. albicans}

There has been a consensus that the yeast-to-hyphae transition is a crucial factor in C. albicans biofilm formation and virulence [24]. Consequently, we decided to investigate the effects of $L$. casei cocultivation on $C$. albicans filamentous growth. Therefore, yeasts were cultivated in the presence of fetal bovine serum (FBS) to allow the formation of hyphae. The SC5314 strain was used due to its recognized ability to quickly form filaments [25]. By microscopic analysis, both C. albicans ATCC90028 and C. albicans SC5314 properly produced germ tubes after $3 \mathrm{~h}$ of induction (data not shown). After $24 \mathrm{~h}$, long hyphae were observed in only the controls (Fig. 2C). On the other hand, when in coculture with $L$. casei, the yeast-to-hyphae transition was strongly impaired compared to the controls, and only a few pseudohyphae and blastoconidia were observed (Fig. 2D).

\section{L. casei Shirota reduces the initial adhesion of Candida biofilms}

Initial adhesion to a surface is the first step in biofilm formation. Since L. casei Shirota impaired the yeast-tohyphae transition, we decided to evaluate the effects of this strain on the initial biofilm formation of Candida strains. After $24 \mathrm{~h}$, a strong and consistent cell layer covering the whole surface was observed in the control sample (Fig. 2A). On the other hand, in the cocultures, the presence of $L$. casei caused a clear reduction in fungal growth, and empty spaces among the few yeast cells remaining as well as many L. casei Shirota cells were observed (Fig. 2B).

Due to the three-dimensional nature of biofilms and the use of optical microscopy, we were not able to visualize fully formed biofilms. However, we demonstrated that $L$. casei Shirota is capable of interfering with the initial adhesion of Candida cells.

\section{Discussion}

VVC is one of the most frequent diagnoses in gynecology and the second most common genital infection globally [1]. One of the main problems associated with these infections is the increasing rate of antifungal therapy failure [7], which leads to episodes of recurrent VVC [17]. This increasing resistance has motivated the search for alternative therapies to control VVC, and the use of Lactobacillus spp. as probiotics is one of the most promising strategies [26].

In this study, L. casei Shirota showed inhibitory activity against all tested Candida strains, which represent the main etiological agents of VVC [5], in addition to the emerging pathogen $C$. auris. Inhibition by $L$. casei
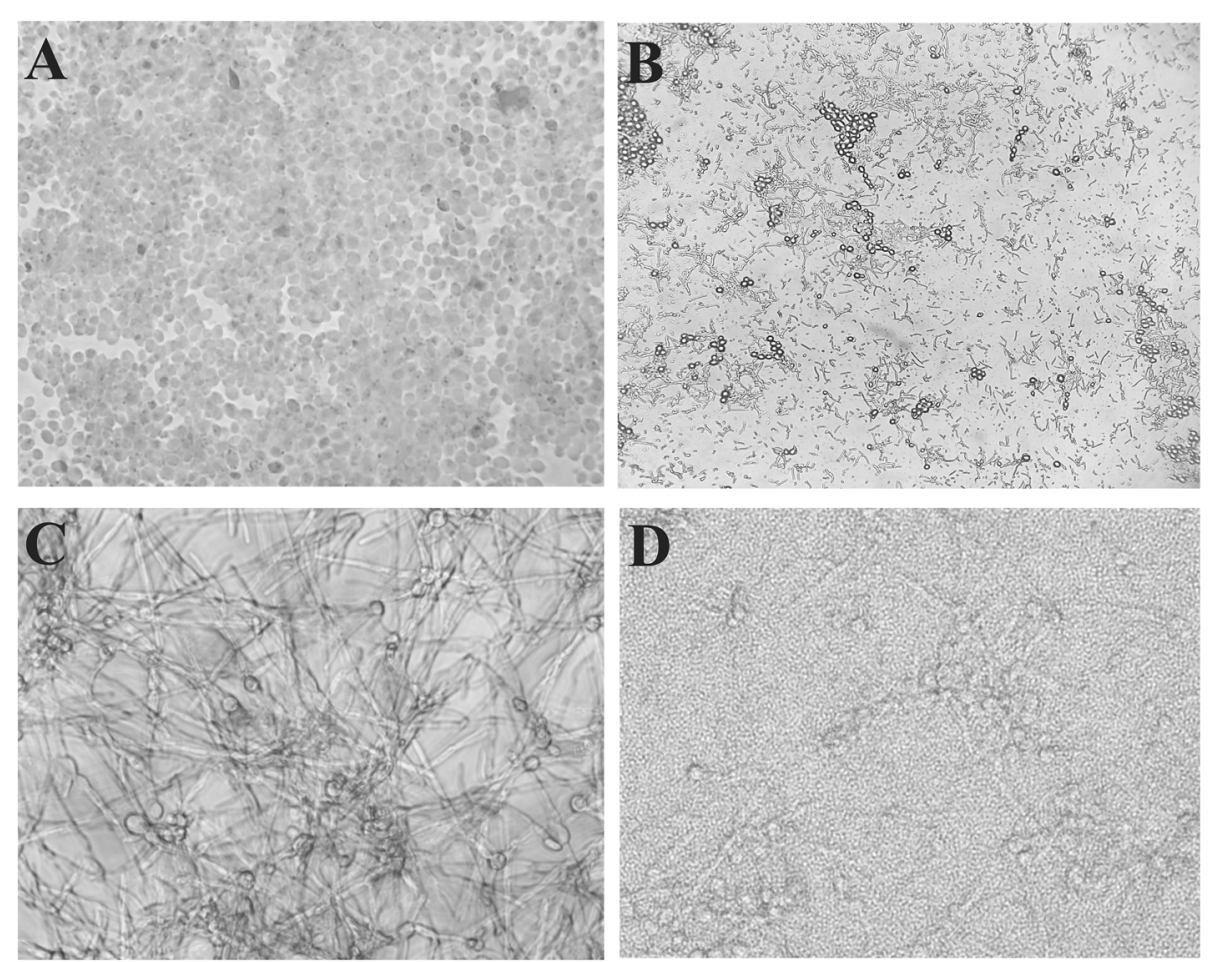

Fig. 2 Effects of L. casei Shirota on the early biofilm formation and hyphal growth of Candida spp. C. albicans 90028 (A) and SC5314 (C) incubated in the presence of serum $(10 \%)$ at $37^{\circ} \mathrm{C}$ for $24 \mathrm{~h}$. Few yeast cells were seen after cocultivation with L. casei Shirota (B). Hyphae formation was strongly impaired when Candida strains were cocultured with L. casei Shirota (D). Magnification 1000× (A, C and D); B 400× 
was very effective $(89.2 \%)$ on the most prevalent species, C. albicans [17], and $95.6 \%$ inhibition was reached against C. tropicalis.

Growth inhibition is probably related to the production of lactic acid since the microdilution tests showed that Candida spp. do not grow at a lactic acid concentration of $5 \mathrm{mg} / \mathrm{mL}$. This result corroborates recent studies that indicate that the production of lactic acid is the main microbicidal factor associated with strains of Lactobacillus [14, 27].

L. casei Shirota was also able to reduce the formation of C. albicans hyphae. Many studies support a strong link between hyphal morphogenesis and C. albicans pathogenicity [24]. In a mouse model of systemic infection, mutant $C$. albicans was unable to switch its form, resulting in significantly reduced virulence [28]. Moreover, the yeast-to-hyphal transition plays a pivotal role in the transition from commensalism to pathogenicity [29]. In patient tissue samples, C. albicans was found predominantly in the hyphal form [24]. Furthermore, hyphal formation was shown to contribute to the ability of C. albicans cells to kill macrophages [30].

Based on our initial data, we hypothesized that $L$. casei Shirota could also have some effect on the formation of early biofilm structures, probably because hyphae were not properly produced. Biofilm structures enable microorganisms to colonize and exacerbate clinical infections through dissemination into the bloodstream [31], leading to invasive systemic infections, which are extremely difficult to eradicate because of their high resistance to antifungal drugs [32].

The primary source of vaginal microbiota is the intestine [33]. After oral administration, probiotic strains of Lactobacillus have already been demonstrated to survive and disperse in the vagina in some studies. Joo [34] demonstrated that $L$. helveticus administered orally or vaginally reduced the growth of Candida in immunosuppressed mice. Falagas [35] reviewed this subject and found evidence in favor of oral supplementation with lactobacilli to prevent VVC. Due to its inhibitory actions against growth and hyphae and early biofilm formation in Candida, $L$. casei Shirota could be an interesting alternative for the management of VVC. A next step would be to perform in vivo trials to confirm this hypothesis.

\section{Conclusion}

This work presents evidence that $L$. casei Shirota derived from fermented milk has microbicidal action against Candida albicans as well as on non-C. albicans strains, which have been found with increasing frequency as etiologic agents of VVC. L. casei Shirota was also shown to have a microbicidal effect on $C$. auris, a multidrugresistant species whose recent emergence is of worldwide concern.

\section{Abbreviations}

WC: Vulvovaginal candidiasis; MIC: Minimum inhibitory concentration; MALDI-TOF: Matrix-Assisted Laser Desorption/lonization Time of Flight; MRS: Man, Rogosa and Sharpe; YM: Yeast and Mold; CFU: Colony-forming units; ATCC: American Type Culture Collection

\section{Acknowledgements}

The authors would like to thank Ildinete Silva Pereira and Jhones do Nascimento Dias for their indispensable assistance.

\section{Authors' contributions}

ALP performed the experiments, AFC designed the study and processed the samples, LCP recruited all patients and collected the patient samples, BMA identified and sent the cultured samples for processing, FBAS performed microscopic analyses and wrote the manuscript, RMA designed the study and wrote the manuscript, YKMN processed all results and wrote the manuscript. All the authors read and approved the final manuscript.

\section{Funding}

"Coordenação de Aperfeiçoamento de Pessoal de Nível Superior" (CAPES) provided a scholarship grant for Aline Paniagua.

\section{Availability of data and materials}

The datasets used and/or analyzed during the current study are available from the corresponding author on reasonable request.

\section{Declarations}

\section{Ethics approval and consent to participate}

The research was carried out in accordance with the principles of the Declaration of Helsinki and approved by the "Comitê de Ética em Pesquisa da Faculdade de Ciências da Saúde da Universidade de Brasília" (Ethics Committee, CEP-FS) through consubstantiated opinion number 3,430,073. All participants signed an informed consent form.

\section{Consent for publication}

Not applicable.

Competing interests

The authors declare that they have no competing interests.

\section{Author details}

${ }^{1}$ Clinical Microbiology and Immunology Laboratory, Department of Pharmacy, University of Brasilia, Campus Darcy Ribeiro, Brasilia, DF 70910-900, Brazil. ${ }^{2}$ Central Public Health Laboratory of the District Federal (LACEN-DF), Medical Biology Management, Center of Parasitology and Mycology, Brasília, DF, Brazil. ${ }^{3}$ Vulvar Pathology Clinic, Department of Gynecology, Brasilia University Hospital, University of Brasilia, Brasilia, DF, Brazil.

Received: 22 May 2020 Accepted: 1 September 2021 Published online: 23 September 2021

\section{References}

1. Rodríguez-Cerdeira C, Gregorio MC, Molares-Vila A, López-Barcenas A, Fabbrocini G, Bardhi B, et al. Biofilms and vulvovaginal candidiasis. Colloids Surf B Biointerfaces. 2019;174:110-25. https://doi.org/10.1016/j.colsurfb.201 8.11.011.

2. Yano J, Sobel JD, Nyirjesy P, Sobel R, Williams VL, Yu Q, et al. Current patient perspectives of vulvovaginal candidiasis: incidence, symptoms, management and post-treatment outcomes. BMC Womens Health. 2019;19:48. https://doi. org/10.1186/s12905-019-0748-8.

3. Gonçalves B, Ferreira C, Alves CT, Henriques M, Azeredo J, Silva S. Vulvovaginal candidiasis: epidemiology, microbiology and risk factors. Crit Rev Microbiol. 2016;42(6):905-27. https://doi.org/10.3109/1040841X.2015.1 091805

4. Deorukhkar SC, Saini S, Mathew S. Non-C. albicans Candida infection: an emerging threat; 2014. https://doi.org/10.1155/2014/615958.

5. Makanjuola O, Bongomin F, Fayemiwo SA. An update on the roles of NonC. albicans Candida species in vulvovaginitis. J Fungi (Basel). 2018:4(4):121. https://doi.org/10.3390/jof4040121. 
6. Behtash A, Nafisi S, Maibach $\mathrm{H}$. New generation of fluconazole: a review on existing researches and technologies. Curr Drug Deliv. 2017;14(1):2-15. https://doi.org/10.2174/1567201813666160502125620.

7. Sobel JD, Sobel R. Current treatment options for vulvovaginal candidiasis caused by azole-resistant Candida species. Expert Opin Pharmacother. 2018; 19(9):971-7. https://doi.org/10.1080/14656566.2018.1476490.

8. Haegler P, Joerin L, Krähenbühl S, Bouitbir J. Hepatocellular Toxicity of Imidazole and Triazole Antimycotic Agents. Toxicological Sciences. 2017; 157(1):183-95. https://doi.org/10.1093/toxsci/kfx029.

9. Marx-Stoelting P, Constanze K, Braeuning A. The Connection of Azole Fungicides with Xeno-Sensing Nuclear Receptors Drug Metabolism and Hepatotoxicity. Cells. 2020;9(5):1192. https://doi.org/10.3390/cells9051192.

10. Wagner $\mathrm{D}$, Johnson SJ. Probiotic lactobacillus and estrogen effects on vaginal epithelial gene expression responses to Candida albicans. J Biomed Sci. 2012;19(1):58. https://doi.org/10.1186/1423-0127-19-58.

11. Leão MVP, Tavares TAA, Gonçalves e Silva CR, dos Santos SSF, Junqueira JC, de Oliveira LD, et al. Lactobacillus rhamnosus intake can prevent the development of Candidiasis. Clin Oral Investig. 2018;22(7):2511-8. https:// doi.org/10.1007/s00784-018-2347-8.

12. Matsubara VH, Bandara HMHN, Mayer MPA, Samaranayake LP. Probiotics as antifungals in mucosal candidiasis. Clin Infect Dis. 2016;62(9):1143-53. https://doi.org/10.1093/cid/ciw038.

13. Kovachev S. Defence factors of vaginal lactobacilli. Crit Rev Microbiol. 2018; 44(1):31-9. https://doi.org/10.1080/1040841X.2017.1306688.

14. Tachedjian G, Aldunate M, Bradshaw CS, Cone RA. The role of lactic acid production by probiotic Lactobacillus species in vaginal health. Res Microbiol. 2017;168(9-10):782-92. https://doi.org/10.1016/j.resmic.2017.04 001.

15. Petrova MI, Lievens E, Shweta M, Imholz N, Lebeer S. Lactobacillus species as biomarkers and agents that can promote various aspects of vaginal health. Front Physiol. 2015;6. https://doi.org/10.3389/fphys.2015.00081.

16. Petrova MI, Gregor R, Vaneechoutte M, Lebeer S. Lactobacillus iners : Friend or Foe?. Trends Microbiol. 2017;25(3):182-91. https://doi.org/10.1016/j.tim.2 016.11.007.

17. Sobel JD. Recurrent vulvovaginal candidiasis. Am J Obstet Gynecol. 2016; 214(1):15-21. https://doi.org/10.1016/j.ajog.2015.06.067.

18. Spivak ES, Hanson KE, Kraft CZ. Candida auris: an Emerging Fungal Pathogen. J Clin MicrobiolC. 2018;56(2). https://doi.org/10.1128/JCM.01588-1 7.

19. Rossoni RD, de Barros PP, Mendonça IDC, Medina RP, Silva DHS, Fuchs BB, Junqueira JC, Mylonakis E. The Postbiotic Activity of Lactobacillus paracase 28.4 Against Candida auris. Front Cell Infect Microbiol. 2020;10. https://doi. org/10.3389/fcimb.2020.00397.

20. Pfaller MA, Haturvedi V, Espinel-Ingroff A, Ghannoum MA, Gosey LL, Odds FC, et al. Reference method for broth dilution antifungal susceptibility testing of yeasts; approved standard - second edition serving the world 's medical science community through voluntary consensus. 2002.

21. Kang MS, Lim HS, Oh JS, Lim YJ, Wuertz-Kozak K, Harro JM, et al. Antimicrobial activity of Lactobacillus salivarius and Lactobacillus fermentum against Staphylococcus aureus. Pathog Dis. 2017;75(2). https://doi.org/10.1 093/femspd/ftx009.

22. Hong SK, Chang BK, Song SH, Kim EC. Use of MALDI-TOF MS technique for rapid identification of bacteria from positive blood cultures. Indian J Med Microbiol. 2014;32(4):419-22. https://doi.org/10.4103/0255-0857.142261.

23. O'hanlon DE, Moench TR, Cone RA. Vaginal pH and microbicidal lactic acid when lactobacilli dominate the microbiota. PLoS One. 2013;8(11):e80074. https://doi.org/10.1371/journal.pone.0080074.

24. Kornitzer D. Regulation of Candida albicans hyphal morphogenesis by endogenous signals. J Fungi (Basel). 2019;5(1):21. https://doi.org/10.3390/ jof5010021.

25. Lagree K, Mon HH, Mitchell AP, Ducker WA. Impact of surface topography on biofilm formation by Candida albicans. PLoS One. 2018;13(6):e0197925. https://doi.org/10.1371/journal.pone.0197925.

26. Kim J-M, Park YJ. Probiotics in the prevention and treatment of postmenopausal vaginal infections: review article. J Menopausal Med. 2017; 23(3):139-45. https://doi.org/10.6118/jmm.2017.23.3.139.

27. Mirmonsef P, Spear GT. The barrier to HIV transmission provided by genital tract Lactobacillus colonization. Am J Reprod Immunol. 2014;71(6):531-6. https://doi.org/10.1111/aji.12232.
28. Lo HJ, Köhler JR, Didomenico B, Loebenberg D, Cacciapuoti A, Fink GR. Nonfilamentous C. albicans mutants are avirulent. Cell. 1997;90(5):939-49. https://doi.org/10.1016/S0092-8674(00)80358-X.

29. Witchley JN, Penumetcha P, Abon NV, Woolford CA, Mitchell AP, Noble SM. Candida albicans morphogenesis programs control the balance between gut commensalism and invasive infection. Cell Host Microbe. 2019;25:432443.e6. https://doi.org/10.1016/j.chom.2019.02.008.

30. McKenzie CGJ, Koser U, Lewis LE, Bain JM, Mora-Montes HM, Barker RN, et al. Contribution of Candida albicans cell wall components to recognition by and escape from murine macrophages. Infect Immun. 2010;78(4):1650-8. https://doi.org/10.1128/IAl.00001-10.

31. Lohse MB, Gulati M, Johnson AD, Nobile CJ. Development and regulation of single-and multi-species Candida albicans biofilms. Nat Rev Microbiol. 2018; 16(1):19-31. https://doi.org/10.1038/nrmicro.2017.107.

32. Nobile CJ, Johnson AD. Candida albicans biofilms and human disease. Annu Rev Microbiol. 2015;69(1):71-92. https://doi.org/10.1146/annurev-micro-091 014-104330.

33. Danielsson D, Teigen PK, Moi H. The genital econiche: focus on microbiota and bacterial vaginosis. Ann N Y Acad Sci. 2011;1230(1):48-58. https://doi. org/10.1111/j.1749-6632.2011.06041.x.

34. Joo HM, Kim KA, Myoung KS, Ahn YT, Lee JH, Huh CS, et al. Lactobacillus helveticus HY7801 ameliorates vulvovaginal candidiasis in mice by inhibiting fungal growth and NF-KB activation. Int Immunopharmacol. 2012; 14(1):39-46. https://doi.org/10.1016/j.intimp.2012.05.023.

35. Falagas ME, Betsi Gl, Athanasiou S. Probiotics for prevention of recurrent vulvovaginal candidiasis: a review. J Antimicrob Chemother. 2006;58(2):26672. https://doi.org/10.1093/jac/dkl246.

\section{Publisher's Note}

Springer Nature remains neutral with regard to jurisdictional claims in published maps and institutional affiliations.
Ready to submit your research? Choose BMC and benefit from:

- fast, convenient online submission

- thorough peer review by experienced researchers in your field

- rapid publication on acceptance

- support for research data, including large and complex data types

- gold Open Access which fosters wider collaboration and increased citations

- maximum visibility for your research: over $100 \mathrm{M}$ website views per year

At $\mathrm{BMC}$, research is always in progress.

Learn more biomedcentral.com/submissions 